\title{
Knowledge and Self-Reported Practice of Universal Precautions among Kuwait University Medical Students in Their Clinical Years
}

\author{
Jumanah Karim Mariam Al-Saraji Fatma Al-Mousawi Zahra Al-Haddad \\ Dina Al-Sharaf Yousef Marwan Saeed Akhtar \\ Department of Community Medicine and Behavioral Sciences, Faculty of Medicine, Health Sciences Center, \\ Kuwait University, Al-Jabriya, Kuwait
}

\section{Key Words}

Universal precautions $\cdot$ Knowledge $\cdot$ Practice $\cdot$ Medical students · Kuwait University

\begin{abstract}
Objectives: This cross-sectional study aimed to assess the knowledge and practice of universal precautions among Faculty of Medicine, Kuwait University, medical students in their clinical years. Subjects and Methods: A self-administered questionnaire including 9 knowledge and 9 practice questions of universal precautions was used. A score was calculated for both knowledge and practice. These scores were dichotomized into less than median score (poor) and more than median score (good). 244 students were invited to participate. Results: Of the 244 students, 220 (90.2\%) accepted to participate. Of the 9 knowledge questions about universal precautions, 7 were answered correctly by more than 60\% (range 64.8-90.4) of the students. All questions regarding the practice of universal precautions were answered correctly by over $60 \%$ (range 61.8-96.4) of the students. The prevalence of poor knowledge was 38.2\% (84/220) and poor practice was $27.7 \%$ (61/220). Grade point average was significantly ( $p=0.008$ ) associated with the knowledge status of the respondents; however, it was not significantly associ-
\end{abstract}

ated ( $p=0.397$ ) with practice of universal precautions. Furthermore, neither the knowledge status nor any of the sociodemographic variables were significantly associated with the practice of universal precautions. Conclusions: A substantial number of students of the Faculty of Medicine, Kuwait University, in their clinical years appeared to have poor level of both knowledge and practice of universal precautions. Efforts are needed to optimize the level of knowledge and practice among students to minimize the risk of preventable infections.

Copyright $\odot 2012$ S. Karger AG, Basel

\section{Introduction}

Healthcare workers and medical students are routinely exposed to a high degree of risk of infection, which is potentially preventable [1-4]. Additionally, for some of these infections, e.g. hepatitis $\mathrm{C}(\mathrm{HCV})$ and acquired immunodeficiency syndrome (AIDS), vaccines are not available. In 1987, the Centers for Disease Control and Prevention (CDC), Atlanta, Ga., USA made recommendations for universal precautions. These universal precautions are infection control guidelines and measures to prevent the transmission of infections through blood and 
other body fluids among patients and healthcare workers [5].

Published literature revealed poor knowledge of and compliance to universal precautions among healthcare workers and students worldwide [6-12]. It was also shown that immediately after graduation many students in Seattle, USA lacked adequate knowledge of universal precautions regarding the ten common clinical procedures of universal precautions [6]. Similarly, an inadequate knowledge of and low compliance with universal precautions among nursing and allied health practitioners has been shown in the UK [7]. Also, it was noted that anesthetists in Australia and New Zealand were not complying with universal precautions [8]. In Nigeria, only $38.8 \%$ of final year medical and nursing students had good knowledge about universal precaution [9]. A low level of compliance with universal precautions had been documented among healthcare workers and medical students in Nigeria, Iran and Indonesia [10-12]. Moreover, some laboratory personnel in Lebanon lacked proper knowledge and practice about how to dispose blood-contaminated waste [13]. In Kuwait, hand hygiene compliance among nursing staff in secondary care hospitals had been reported to be poor [14].

During the last 5 years, there has been a change in the medical teaching curriculum in the Faculty of Medicine, Kuwait University. However, the new curriculum seemingly has not been adjusted for the new bedside teaching program by introducing the principles of universal precautions. Both the new and old curricula introduced general prevention guidelines early during the first preclinical year, without stressing universal precautions. Thus far, to our knowledge, no study has assessed the understanding and application of CDC-recommended universal precautions among medical students of the Faculty of Medicine, Kuwait University. Therefore, the aim of this cross-sectional study was to assess the extent of knowledge and measure the degree of self-reported adherence to universal precautions of medical students during their clinical rotations. Also, the associations of several demographic factors with the level of knowledge and practice of universal precautions were explored in this sample.

\section{Subjects and Methods}

\section{Study Design and Participants}

This cross-sectional study was conducted in October 2010 to assess the knowledge and self-reported application of universal precautions among medical students in their 5th, 6th or 7th clinical years. On an average, annually around 100 new students are admitted in the FOM. The curriculum consists of seven years of study. The 1st year is premedical (phase I in the new curriculum), the 2 nd to 4 th are pre-clinical years (phase II in the new curriculum), and the 5th to 7th clinical years (phase III in the new curriculum). Students of the new curriculum were only in 5th and 6 th years of study during the time of data collection. The population of our study is medical students in their clinical years of both, the old (5th, 6th and 7th) and new (5th and 6th) curricula. The total number of students registered in these years was 276 .

\section{Questionnaire Development and Pretesting}

A structured and self-administered questionnaire in English was used to collect the information. The study questionnaire had two main sections with 30 questions. Section I was on sociodemographic characteristics (10 questions), including age, gender, nationality, marital status, governorate, family income, year of study, type of curriculum, grade point average (GPA) and the current rotation. Section 2 was on universal precautions (20 questions). It was subdivided into two subsections: (a) to assess student's knowledge regarding universal precautions (11 questions) that included a question regarding the knowledge of the term 'universal precautions' (i.e. whether or not the students had heard or read about the term, and (b) the self-reported practice of these precautions (9 questions). The questions included in section 2 were essentially derived from the CDC recommendations and used by others [11]. The questionnaire was pretested on 34 randomly selected medical students in their clinical years.

\section{Sample Size and Data Collection}

Of the 276 registered students, 244 were contacted and 220 agreed to participate in the study and were therefore interviewed. This sample size was large enough to estimate a prevalence of $23 \%$ of knowledge or poor practice in this population, assuming a 95\% CI, with absolute precision of $5 \%$ around the estimate [15]. The students were invited to participate in the study without consideration of grades, position or any other factor and were approached during problem-based learning sessions or break period.

\section{Ethical Considerations}

Written informed consent was obtained from each participant after an explanation of the study objectives. Participants were assured that participation in the study was voluntary and the confidentiality of the information obtained would be maintained. Permission to administer the questionnaire to the study population was obtained from the Vice Dean, Academics, Faculty of Medicine, Kuwait University. The study protocol and data collection instrument were reviewed and approved by the Ethics Committee and the Department of Community Medicine and Behavioral Sciences.

\section{Statistical Analysis}

Data were analyzed using the Statistical Package for the Social Sciences (SPSS) version 19. Descriptive statistics for sociodemographic variables, frequencies (\%) of correct answers for knowledge and practice questions on universal precautions, and scores for each participant based on the correct answers separately for the knowledge and practice questions were computed. Moreover, the knowledge and practice scores at their median values were dichotomized to create binary variables, i.e. knowledge $(1=$ poor 
Table 1. Knowledge of universal precautions among medical students of Kuwait University in their clinical years, academic year $2010 / 2011(n=220)$

Characteristic

Correct answer

$\mathrm{n}$ $\%$

Infection control guidelines are applied to patients with HIV and HBV only (F)

$183 \quad 85.1$

Infection control guidelines should be applied to all persons regardless of their infection status ( $\mathrm{T}$ )

$152 \quad 69.7$

Infection control guidelines are not necessary in situations that might lead to contact with saliva (T)

$30 \quad 13.7$

Isolation is necessary for patients with blood-borne infections $(\mathrm{F})$

$143 \quad 65.3$

Used needles can be recapped after giving an injection $(\mathrm{F})$

19790.4

For decontamination of devices such as manometer (with only contact with skin) washing with usual detergent is enough $(\mathrm{T})$

Subcutaneous injuries during intravenous injections are the most common cause of occupational infections (T)

Health care workers with non-intact skin should not be involved in direct patient care until the condition resolves (T)

Blood spills should be cleaned up promptly with sodium hypochlorite (T)

$\mathrm{T}=$ True; $\mathrm{F}=$ false

knowledge if the score $<$ median; $0=$ good knowledge, if the score $\geq$ median) and practice ( $1=$ poor practice if the score $<$ median; $0=$ good practice if the score $\geq$ median). Subsequently, the status of knowledge score (poor vs. good) and the status of practice score (poor vs. good) were considered to be outcome variables and the relationship of sociodemographic variables with these two outcome variables were evaluated using $\chi^{2}$ analyses or $\chi^{2}$ analysis for trend in case of ordinal variables. When expected cell frequencies for a variable were less than five, the Fisher-Freeman-Halton exact test was used to evaluate the potential association. For the variables that the practice score status was the outcome, the knowledge score status was also included as an independent variable to evaluate whether poor knowledge translates into poor practice in our study population.

\section{Results}

\section{Characteristics of the Participants}

Of the 220 students, 118 (53.6\%) were females. The majority $(120 ; 54.5 \%)$ were older than 22 years of age. The number of Kuwaitis was 193 (87.7\%), and 178 (80.9\%) were unmarried. 204 (92.7\%) students had a total family income of 1,000 Kuwaiti Dinar (KD) or more per month ( $1 \mathrm{KD}=3.6 \mathrm{USD})$. The participants lived mostly in Hawalli $(80 ; 36.4 \%)$ and Al-Asimah $(61 ; 27.7 \%)$, with a very small number living in Al-Ahmadi $(8 ; 3.6 \%)$ and Al-Jahra (7; 3.2\%). Two thirds of the participants, 146 $(66.4 \%)$, were studying in the new curriculum, mostly 5 th year students (86; 39.1\%). 142 (64.5\%) students were either in medical or surgical rotations. The self-reported GPA of 99 (45.0\%) students was between 2.5 and 2.99 out of 4.0 , with $13(5.9 \%)$ students with a GPA of over 3.5 out of 4.0 .

\section{Knowledge and Practice of Universal Precautions}

Of the study participants, 74 (33.6\%) students had heard and/or read about the term 'universal precautions' previously. $55(74.3 \%)$ of them first heard this term during university teaching sessions, 9 (12.2\%) during hospital teaching sessions, 4 (5.4\%) from friends and $6(8.1 \%)$ from other sources.

Seven out of the nine knowledge questions regarding universal precautions were answered correctly by the majority of the students. However, 30 (13.6\%) participants knew that infection control guidelines are not necessary in situations that might lead to contact with saliva, and 95 (43.2\%) knew that it was enough to use usual detergents to decontaminate devices that have contact only with the skin (table 1). All the questions regarding the practice of universal precautions were answered correctly by more than $60 \%$ of the students. 203 (92.3\%) students disposed of used needles in a sharp box after injections and washed their hands after each contact with a patient (table 2). Of the total possible score of 9 each for knowledge and practice, the median scores for knowledge and practice were 6 and 7, respectively. This yielded the prevalence of poor knowledge and poor practice as 38.6\% (85) and $27.7 \%(61)$, respectively.

Of the sociodemographic variables, current GPA of the respondents showed a significant $(\mathrm{p}=0.008)$ positive association with the knowledge score status, i.e. with im- 
Table 2. Practice of universal precautions among medical students of Kuwait University in their clinical years, academic year $2010 / 2011$ $(\mathrm{n}=220)$

Characteristic

Correct answer

$\mathrm{n}$

I assume that blood and all body fluids of patients are infectious (T)

170

77.3

I wear mask, gown and eye wear if procedures and patient care activities are likely to cause splashing of blood and deep body fluids (T)

I dispose of used needles into a sharp box after injection ( $\mathrm{T}$ )

I wear gloves as the first step in cleaning surfaces contaminated with blood or other body fluids (T)

Washing with soap and water for 5 minutes is my first step after contact with contaminated material (T)

I apply infection control guidelines in situations that might lead to contact with sweat $(\mathrm{F})$

If I have a wound, I wear gloves before caring for patients $(\mathrm{T})$

I wear sterile gloves for procedures involving contact with normally sterile areas of the patient's body (T)

When dealing with patients, I wash my hands after each contact with a patient (T)

$175 \quad 79.9$

$203 \quad 92.3$

$188 \quad 85.8$

$137 \quad 62.6$

$136 \quad 61.8$

$177 \quad 80.5$

$147 \quad 67.1$

21296.4

$\mathrm{T}=$ True $; \mathrm{F}=$ false.

proved GPA there was a tendency of improved knowledge score (table 3 ). None of the sociodemographic variables were significantly associated with practice score status (table 4). However, some differences in the proportions of universal precautions practice scores by some sociodemographic variables were noted. For example, more Kuwaiti $(56 ; 29.0 \%)$ than non-Kuwaiti students $(5 ; 19.2 \%)$ had a poor practice score. In addition, a higher proportion $(22 ; 30.6 \%)$ of 6 th year students had a poor practice score compared to 5 th $(23 ; 26.6 \%)$ and 7 th (16; $25.8 \%)$ year students. Furthermore, $45 \%$ of the students currently in pediatrics rotation had a poor practice score compared to less than $30 \%$ in each of all the other four rotations (Medicine, Surgery, Community Medicine, and Obstetrics and Gynecology. 26 (31\%) students who had a poor knowledge score also had a poor practice score.

\section{Discussion}

In this cross-sectional study, only $33.5 \%$ of the participants had heard about the term 'universal precautions' previously and this percentage is much lower than a $53.5 \%$ reported among medical students in Iran [11]. The difference could possibly be attributed to the poor attendance rate in classroom teaching and discussions among students of the Faculty of Medicine, Kuwait University. It could also be due to more emphasis on the concept of universal precautions in Iran compared to that of this institution.

Universal Precautions among Medical Students
Poor knowledge (38.4\%) and poor practice (27.7\%) of universal precautions were similar to those in Iranian study [11] to final year medical students in the University of Washington School of Medicine [6] and the poor knowledge and poor practice are worrisome.

The only $13.7 \%$ of the participants who correctly answered the question regarding the necessity of universal precautions in situations involving contact with saliva is not alarming because saliva is one of the body secretions that perhaps do not require such precautions [5].

The $90.4 \%$ of the participants in our study who knew that needles should not be recapped after use was higher than 58\% reported in the Iranian study. Furthermore, compared to $77.3 \%$ of the students in our study, $100 \%$ of the students in an Iranian study thought that blood and all bodily fluids of patients are infectious [11]. These differences between students of two medical colleges may be due to the institutional difference in the methods of guiding the students on the application of universal precautions.

While there was no relationship between the level of knowledge and actual practice of universal precautions in our study; a significant positive association $(p<0.001)$ was recorded between knowledge and practice among the students in the Iranian study [11]. Many researches have shown that people with a good practice are not necessarily knowledgeable and vice versa [16]. Studies done among healthcare workers in Pakistan and Texas, USA, found the disparity between the level of knowledge and actual practice of universal precautions $[17,18]$. These studies consistently found that the optimal practice 
Table 3. $\chi^{2}$ analyses of the relationships of sociodemographic characteristics and knowledge score of universal precautions among medical students of Kuwait University in their clinical years, academic year 2010/2011 $(n=220)$

\begin{tabular}{|c|c|c|c|}
\hline Characteristic & Total & $\begin{array}{l}\text { Poor knowledge } \\
\text { score status } \\
(\mathrm{n}=84)\end{array}$ & $\begin{array}{l}\mathrm{p} \\
\text { value }\end{array}$ \\
\hline \multicolumn{4}{|l|}{ Age $^{a}$} \\
\hline$\leq 22$ years & 97 & $34(35.1 \%)$ & \multirow[t]{2}{*}{0.426} \\
\hline$>22$ years & 119 & $48(40.3 \%)$ & \\
\hline \multicolumn{4}{|l|}{ Gender } \\
\hline Male & 101 & $41(40.6 \%)$ & \multirow[t]{2}{*}{0.561} \\
\hline Female & 117 & $43(36.8 \%)$ & \\
\hline \multicolumn{4}{|l|}{ Nationality } \\
\hline Kuwaiti & 193 & $73(37.8 \%)$ & \multirow[t]{2}{*}{0.550} \\
\hline Non-Kuwaiti & 25 & $11(44.0 \%)$ & \\
\hline \multicolumn{4}{|l|}{ Marital status ${ }^{\mathrm{a}}$} \\
\hline Unmarried & 177 & $69(39.0 \%)$ & \multirow[t]{2}{*}{0.565} \\
\hline Married & 41 & $14(34.1 \%)$ & \\
\hline \multicolumn{4}{|l|}{ Total family income } \\
\hline$<1,000 \mathrm{KD} / \mathrm{month}$ & 15 & $8(53.3 \%)$ & \multirow[t]{3}{*}{$0.698^{\mathrm{b}}$} \\
\hline $1,000-2,000 \mathrm{KD} /$ month & 88 & $31(35.2 \%)$ & \\
\hline$>2,000 \mathrm{KD} / \mathrm{month}$ & 116 & $45(38.8 \%)$ & \\
\hline \multicolumn{4}{|l|}{ Governorate } \\
\hline Al-Ahmadi & 8 & $4(50.0 \%)$ & \multirow[t]{6}{*}{0.210} \\
\hline Al-Asimah & 61 & $23(37.7 \%)$ & \\
\hline Al-Farwaniyah & 27 & $14(51.9 \%)$ & \\
\hline Al-Jahra & 7 & $4(57.1 \%)$ & \\
\hline Hawalli & 80 & $31(38.8 \%)$ & \\
\hline Mubarak Al-Kabeer & 35 & $8(22.9 \%)$ & \\
\hline \multicolumn{4}{|l|}{ Type of curriculum } \\
\hline New curriculum & 146 & $58(39.7 \%)$ & \multirow[t]{2}{*}{0.555} \\
\hline Old curriculum & 73 & $26(35.6 \%)$ & \\
\hline \multicolumn{4}{|l|}{ Year of study } \\
\hline 5 th & 86 & $31(36.0 \%)$ & \multirow[t]{3}{*}{$0.920^{\mathrm{b}}$} \\
\hline 6 th & 72 & $31(43.1 \%)$ & \\
\hline 7 th & 61 & $22(36.1 \%)$ & \\
\hline \multicolumn{4}{|l|}{ Current rotation } \\
\hline Medicine & 68 & $27(39.7 \%)$ & \multirow[t]{5}{*}{0.924} \\
\hline Surgery & 73 & $27(37.0 \%)$ & \\
\hline Community medicine & 28 & $9(32.1 \%)$ & \\
\hline Obstetrics and gynecology & 30 & $13(43.3 \%)$ & \\
\hline Pediatrics & 20 & $8(40.0 \%)$ & \\
\hline \multicolumn{4}{|l|}{ Grade point average (GPA) $)^{a}$} \\
\hline$\geq 3.5$ & 13 & $0(0.00 \%)$ & \multirow[t]{4}{*}{$0.008^{c}$} \\
\hline $3.0-3.49$ & 34 & $17(50.0 \%)$ & \\
\hline $2.5-2.99$ & 99 & $40(40.4 \%)$ & \\
\hline$<2.5$ & 52 & $21(40.4 \%)$ & \\
\hline
\end{tabular}

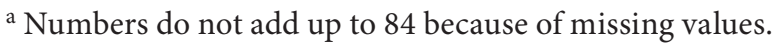

${ }^{\mathrm{b}}$ Linear-by-linear association.

${ }^{\mathrm{c}}$ Fisher-Freeman-Halton exact test.
Table 4. $\chi^{2}$ analyses of the relationships of sociodemographic characteristics and knowledge score, with the practice score of universal precautions among medical students of Kuwait University in their clinical years, academic year 2010/2011 $(n=220)$

\begin{tabular}{llll}
\hline Characteristic & Total & $\begin{array}{l}\text { Poor practice } \\
\text { score status } \\
(\mathrm{n}=61)\end{array}$ & value \\
& &
\end{tabular}

Age $^{\mathrm{a}}$

\section{$\leq 22$ years}

$>22$ years

$\begin{array}{rlr}97 & 24(24.7 \%) & 0.389 \\ 120 & 36(30.0 \%) & \\ 101 & 27(26.7 \%) & 0.732 \\ 118 & 34(28.8 \%) & \end{array}$

Gender

Female $118 \quad 34(28.8 \%)$

Nationality

Kuwaiti

Non-Kuwaiti

$193 \quad 56(29.0 \%)$

0.296

Marital status

Unmarried

Married

Total family income

$<1,000 \mathrm{KD} /$ month

1,000-2,000 KD/month

$>2,000 \mathrm{KD} / \mathrm{month}$

$26 \quad 5(19.2 \%)$

$178 \quad 48(27.0 \%) \quad 0.542$

$41 \quad 13(31.7 \%)$

$16 \quad 6(37.5 \%) \quad 0.064^{\mathrm{b}}$

$88 \quad 29(33.0 \%)$

$116 \quad 26(22.4 \%)$

Governorate

Al-Ahmadi

Al-Asimah

Al-Farwaniyah

Al-Jahra

Hawalli

Mubarak Al-Kabeer

Type of curriculum

New curriculum

Old curriculum

Year of study

$$
5 \text { th }
$$

6 th

7 th

Current rotation

Medicine

Surgery

Community medicine

Obstetrics and gynecology

Pediatrics

$\begin{array}{rrr}8 & 3(37.5 \%) & 0.556 \\ 61 & 20(32.8 \%) & \\ 27 & 10(37.0 \%) & \end{array}$

$7 \quad 2(28.6 \%)$

$80 \quad 18(22.5 \%)$

$36 \quad 8(22.2 \%)$

$146 \quad 42(28.8 \%)$

146
74

0.628

$86 \quad 23(26.7 \%)$

$0.949^{b}$

$72 \quad 22(30.6 \%)$

$62 \quad 16(25.8 \%)$

$69 \quad 19(27.5 \%)$

0.481

$73 \quad 19(26.0 \%)$

$28 \quad 7(25.0 \%)$

$30 \quad 7(23.3 \%)$

$20 \quad 9(45.0 \%)$

Grade point average (GPA) ${ }^{\mathrm{a}}$

$\geq 3.5$

3.0-3.49

$2.5-2.99$

$2(15.4 \%)$

$0.397^{\mathrm{b}}$

$<2.5$

Knowledge score status
Poor
Good
$84 \quad 26(31.0 \%)$
$135 \quad 35(25.9 \%)$

\section{3}

$10(28.6 \%)$

$26(26.3 \%)$

$16(30.8 \%)$

$0.772^{\mathrm{c}}$

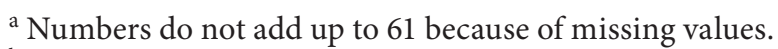

${ }^{\mathrm{b}}$ Linear-by-linear association.

${ }^{\mathrm{c}}$ Fisher-Freeman-Halton exact test. 
score was less than the level of knowledge of universal precautions among healthcare workers. Several plausible explanations may explain this opposing relationship between the knowledge and practice of universal precautions including the fact that students know the information but translating knowledge into actual practice depends upon many personal attributes including personality, feeling of inconvenience, pressure of work, time limitations, etc.

\section{Conclusion}

This study showed a high prevalence of poor knowledge and poor practice of universal precautions among medical students in the Faculty of Medicine, Kuwait University and raises the need to address these issues during the clinical years. Any gaps in the knowledge and practice of universal precautions among upcoming physicians and surgeons in our and similar settings should be addressed during their formative years and be evaluated subsequently.

\section{References}

1 McCormick RD, Meisch MG, Ircink FG, Maki DG: Epidemiology of hospital sharps injuries: a 14-year prospective study in the pre-AIDS and AIDS eras. Am J Med 1991;91: 301s-307s.

2 APIC Position Paper: Prevention of devicemediated blood borne infections to health care workers. Am J Infect Control 1998;26: 570-580.

- 3 Birenbaum D, Wohl A, Duda B, Runyon M, Stearns B, Willett M: Medical students' occupational exposures to potentially infectious agents. Acad Med 2002;77:185-189.

-4 Beltrami EM, Williams IT, Shapiro CN, Chamberland ME: Risk and management of blood-borne infections in health care workers. Clin Microbiol Rev 2000;13:385-407.

5 Center for Disease Control: Universal precautions for prevention of transmission of HIV and other bloodborne infections (http://www.cdc.gov/ncidod/dhqp/bp_universal_precautions.html).

$\checkmark 6$ Koenig S, Chu J: Senior medical students' knowledge of universal precautions. Acad Med 1993;68:372-374.

7 Gammon J, Gould D: Universal precautions: a review of knowledge, compliance and strategies to improve practice. J Res Nurs 2005; 10: 529-547.
8 Richards MJ, Jenkin GA, Johnson PD: Universal precautions: attitudes of Australian and New Zealand anaesthetists. Med J Aust 1997;166:141-142.

9 Bamigboye AP, Adesanya AT: Knowledge and practice of universal precautions among qualifying medical and nursing students: a case of Obafemi Awolowo University teaching hospitals complex, ILE-IFE. Res J Med Med Sci 2006;1:112-116.

10 Sadoh WE, Fawole AO, Sadoh AE, Oladimeji AO, Sotiloye OS: Practice of universal precautions among healthcare workers. J Natl Med Assoc 2006;98:722-726.

-11 Motamed N, BabaMahmoodi F, Khalilian A, Peykanheirati M, Nozari M: Knowledge and practices of health care workers and medical students towards universal precautions in hospitals in Mazandaran Province. East Mediterr Health J 2006;12:653-661.

-12 Mukti A, Treloar C, Suprawimbarti, Asdie AH, D’Este K, Higginbotham N, Heller R: A universal precautions education intervention for health workers in Sardjito and PKU hospital Indonesia. Southeast Asian J Trop Med Public Health 2000;31:405-411.
3 Kahhaleh JG, Jurjus AR: Adherence to universal precautions among laboratory personnel in Lebanon. East Mediterr Health J 2005;11:929-942.

14 Al-Wazzan B, Salmeen Y, Al-Amiri E, Abul A, Bouhaimed M, Al-Taiar A: Hand hygiene practices among nursing staff in public secondary care hospitals in Kuwait: self-report and direct observation. Med Princ Pract 2011;20:326-331.

15 Lemeshow S, Hosmer DW Jr, Klar J, Lwanga SK: Adequacy of Sample Size in Health Studies. New York, Wiley, 1990, pp 1-240.

16 Hesse AAJ, Adu-Aryee NA, Entsua-Mensah $\mathrm{K}, \mathrm{Wu} \mathrm{L}$ : Knowledge, attitude and practice universal basic precautions by medical personnel in a teaching hospital. Ghana Med J 2006;40:61-64.

17 Salehi AS, Garner P: Occupational injury history and universal precautions awareness: a survey in Kabul hospital staff. BMC Infect Dis 2010;10:19.

18 Helfgott AW, Taylor-Burton J, Garcini FJ, Eriksen NL, Grimes R: Compliance with universal precautions: knowledge and behavior of residents and students in a department of obstetrics and gynecology. Infect Dis Obstet Gynecol 1998;6:123-128. 